\title{
Основы формирования модельных характеристик психоэмоционального состояния и профиля состояния психической готовности футболистов
}

\author{
Козлов А.A.* \\ Акционерное общество «Футбольный клуб «Ростов» \\ г. Ростов-на-Дону, Россия \\ ORCID: oooo-ooo3-1075-4423, Stim.alexei@yandex.ru*
}

\begin{abstract}
Аннотация: Современный спорт высших достижений в игровых видах спорта требует индивидуализированного подхода ко всем видам спортивной подготовки. В первую очередь необходимо определить критерии индивидуализации не только физической, но и психологической подготовки. Разработку модельной характеристики психоэмоционального состояния и профиля состояния психической готовности можно рассматривать как условие повышения эффективности управления спортивной подготовкой на основе расширения возможностей интегральной подготовки футболистов. Исследуемые показатели психоэмоционального состояния и состояния психической готовности могут быть использованы как рычаг эффективного управления спортивной подготовкой, особенно на этапах коррекции тренировочных воздействий каждого футболиста. Отмечено, что при одинаковых условиях физической подготовленности футболистов наблюдаются срывы адаптации в основных и ответственных матчах в случае несвоевременной саморегуляции психического состояния. Мотивация игроков на результативность игры требует оперативности поступления информации не только физического, но и психического состояния. Это требует своевременного проведения диагностики с учетом модельных значений. Методы и материалы исследования. С помощью активациометра (аппарат «АЦ-9К») проведено исследование структурных составляющих психоэмоционального состояния футболистов на тренировочном этапе подготовки. Определены структурные компоненты состояния психической готовности: мотивация достижения цели, склонность к риску и уверенность. Результаты. Выявлены основные факторы, определяющие изменения тактики игры футболистов. Определена значимость психологической подготовки как фактора успешности и результативности матчей при равных условиях готовности футболистов. Разработан модельный диапазон показателей психоэмоционального состояния и профиль состояния готовности футболистов в возрастных периодах 15-17 лет, 18-20 лет и 21-23 года. Заключение. Психоэмоциональное состояние футболистов зависит от возраста и от этапов подготовки. Учет модельного уровня и профиля психоэмоционального состояния и состояния психической готовности футболистов позволяет планировать подготовку с расширенным применением психорегулирующих средств подготовки.

Ключевые слова: игровая деятельность, модельные характеристики, футболисты, психологическая подготовка, психоэмоциональное состояние, состояние психической готовности, профиль.
\end{abstract}

Для цитирования: Козлов А.А.* Основы формирования модельных характеристик психоэмоционального состояния и профиля состояния психической готовности футболистов. Педагогико-психологические и медико-биологические проблемы физической культуры и спорта. 2020; 15(4): 71-77. DOI: 10.14526/2070-4798-2020-15-4-71-77

\section{The formation basis of model characteristics of football players' psycho- emotional state and the profile of psychic readiness state}

\author{
Aleksej A. Kozlov* \\ Football club "Rostov" Joint-Stock Company \\ Rostov-on-Don, Russia \\ ORCID: oooo-ooo3-1075-4423, Stim.alexei@yandex.ru*
}

Abstract: Modern sport of higher achievements in games demands individualized approach to all kinds of sports training. First of all it is necessary to define both the individualization criteria 
of physical and psychological training. Model characteristic of psycho-emotional state and the profile of psychic readiness state creation can be considered as the condition for the effectiveness increase of sports training management on the basis of integral training opportunities broadening among football players. The studied psycho-emotional state and psychic readiness indices can be used as the means of effective sports training management, especially at the stages of each football player's training influences correction. It is defined that in terms of equal conditions of physical readiness in football players we see adaptation disorders in the main and important matches in case of untimely psychic state self-regulation. Players' motivation for game effectiveness demands quick information presentation concerning not only physical, but also psychic state. It demands timely diagnostics, taking into account model values. Research methods. With the help of activationmeter ("ATS-9K" apparatus) we studied structural components of football players' psycho-emotional state at the training stage. We revealed structural components of psychic readiness state: motivation of aim achievement, the tendency to risk and confidence. Results. We revealed the main factors, which condition changes of game tactics among football players. We defined the importance of psychological training as the factor of matches success and effectiveness in terms of football players' readiness equal conditions. We created model range of psycho-emotional state indices and the profile of readiness state in football players at the age of 15-17, 18-20 and 21-23. Conclusion. Football players' psycho-emotional state depends on age and on the stages of training. Taking into account model level and profile of psycho-emotional state and the state of football players' psychic readiness helps to plan training with the broadened use of psycho-regulating means.

Keywords: game activity, model characteristics, football players, psychological training, psycho-emotional state, the state of psychic readiness, profile.

For citation: Aleksej A. Kozlov*. The formation basis of model characteristics of football players' psychoemotional state and the profile of psychic readiness state. Russian Journal of Physical Education and Sport. 2020; 15(4): 71-77. DOI: 10.14526/2070-4798-2020-15-4-71-77.

\section{АКТУАЛЬНОСТЬ}

Футбол является наиболее популярным игровым видом спорта. Международная федерация футбола объединяет различные национальные федерации и ассоциации.

Наиболее характерной тенденцией развития современного футбола является увеличение различных турнирных игр, а также интенсивности и техничности игр. В современных турнирах по футболу отмечается увеличение числа единоборств, которое приводит к жесткости и напряженности матчей. Успешность игр многие специалисты связывают с повышением инициативности многих команд-победителей наравне с высокой физической готовностью. В условиях, когда игры проводятся через день, повышается не только физическая, но и психологическая нагрузка. Проведенный теоретический анализ работ авторов показал, что важна индивидуализация средств саморегуляции спортсменов как фактор повышения эффективности и результативности игр.

А.В. Петухов в своей монографии широко освещает недостатки традиционного метода подготовки футболистов, обращая внимание на необходимость выявления факторов, влияющих на успешность подготовки [4].

Анализ

технико-тактической подготовленности высококлассных футболистов говорит о том, что большой объем скоростной работы, количество технико-тактических действий и увеличение их во вторых таймах игр свидетельствуют о хорошей общей и скоростной выносливости футболистов.

Анализ результатов крупнейших матчей, а также параметров соревновательной деятельности футболистов различного амплуа позволил выявить особенности деятельности ведущих команд мирового масштаба.

По мнению специалистов по различным видам спорта, подобная информация необходима и важна для определения основных тенденций развития современного футбола [1,2,3,5,6].

Проведенный анализ международных игр показал, что современный футбол стал привлекательным и зрелищным. Это способствовало изменению не только правил, но и содержания самих игр. Увеличился общий объем технико-тактических действий игроков 
различных игровых амплуа. Они стали играть быстрее и эффективнее. Существенно повысился класс игры футболистов. Увеличилось число команд, которые могли бы побороться с уже признанными лидерами, что привело к психологическому накалу матчей $[7,8]$.

Повысилось число игр, где требуется предельная мобилизация не только физических сил, но и морально-волевых качеств. Повысился психологический накал из-за непредсказуемости исхода матчей. Увеличился исход матчей, где выигрыш определялся разницей в один мяч. В связи с этим можно отметить, что сегодня футбол становится быстрее, жестче и интенсивнее. Сегодняшние матчи требуют от каждого игрока до конца играть в полную силу.

$$
\text { C увеличением физической, }
$$

функциональной и психологической нагрузки стал востребованным учет психоэмоционального состояния, влияющий на тактическую модель игры футболистов. На игрока влияет не только физическая подготовленность, но и психологическая ответственность за игру [4]. Иногда повышенные требования приводят к различным срывам адаптации игроков.

Важным компонентом психологической подготовки футболистов является формирование микросреды в коллективе и в команде в целом. Требуется постоянная стимуляция для поддержания оптимального психологического климата в команде и среди самих игроков. Важным компонентом состояния психической готовности футболистов выступает формирование мотивации достижения цели, склонности к риску и избеганию неудач. Особо остро ставится вопрос обучения футболистов приемам самоконтроля и саморегуляции психического состояния и психоэмоционального фона.

С учетом того, что в научных работах специалистов большое внимание уделяется методикефизической,техническойитактической подготовки футболистов к соревновательной деятельности, актуализируется психологическая сторона подготовки. Доля соревнований на занятиях занимает 45\% от общего объема всей подготовки. Учет наиболее вероятных видов психического напряжения, влияющих на состояние психической готовности и на психоэмоциональное состояние футболистов, может выступать фактором успеха. Этому уделяется незначительное внимание, акцент делается на совершенствование тактической игры, направленной на опережение соперников по быстроте ведения матча.

Специалистами широко изучаются вопросы психологической подготовки. В командах работают психологи, которые применяют психолого-педагогические методы воздействия на спортсменов. Однако мало освещены вопросы, связанные с формированием высокого уровня состояния психической готовности футболистов на весь турнир и спортивный сезон в целом [9,10].

Цель работы: рассмотрение структурных компонентов состояния психической готовности футболистов одного спортивного сезона игр.

Задачи исследования:

1. Провести изучение и анализ показателей психоэмоционального состояния футболистов тренировочного этапа подготовки.

2. Определить показатели, выступающие как модельные характеристики психоэмоционального состояния футболистов в возрастном аспекте.

3. Составить профили состояния психической готовности футболистов с учетом трех структурных компонентов.

\section{МАТЕРИАЛЫ И МЕТОДЫ}

В исследовании принимали участие футболисты спортивных школ, по 22 человека в каждой группе. Полученные результаты не представлены в других публикациях ранее. Возрастной диапазон исследуемых футболистов составил 15-17 лет; 18-20 лет; 21-23 года. Оценено психоэмоциональное состояние футболистов с использованием аппарата типа «АЦ-9К» [7].

\section{РЕЗУЛЬТАТЫ И ОБСУЖДЕНИЕ}

Анализ научно-методической и специальной литературы позволил подчеркнуть основные тенденции изменения тактики игры:

разнонаправленность технико- 
тактических действий;

- изменение технологий подготовки поля и инвентаря;

- повышение скорости игры;

- повышение активности сопротивления соперников;

проявление упражнений сложнокоординационной направленности;

- разносторонность реализации техники;

- совершенствование тактических схем игр соперников.

Bсе вышеперечисленные факторы способствуют разработке инновационных методик спортивной подготовки футболистов с акцентом на психологическую составляющую.

В таблице 1 представлены показатели психоэмоционального состояния футболистов за один спортивный сезон игр с учетом проявления минимальных и максимальных значений, встречаемых в выборке.

Таблица 1 - Показатели психоэмоционального состояния футболистов за спортивный сезон

\begin{tabular}{|c|c|c|c|}
\hline \multirow{2}{*}{$\begin{array}{c}\text { Показатели психоэмоционального } \\
\text { состояния }\end{array}$} & \multicolumn{2}{|c|}{ Исследуемый возраст футболистов } \\
\cline { 2 - 4 } & $15-17$ лет & $18-20$ лет & $21-23$ года \\
\hline $\begin{array}{c}\text { Точность реакции на движущий } \\
\text { объект, ус.ед. }\end{array}$ & $18,0-25,4$ & $18,5-30,0$ & $20,5-32,0$ \\
\hline $\begin{array}{c}\text { Коэффициент силы нервной } \\
\text { системы, \% }\end{array}$ & $14,5-19,5$ & $14,5-20,5$ & $14,5-22,5$ \\
\hline $\begin{array}{c}\text { Количество движений за 5 с } \\
\text { Коэффициент чувства темпа, ус.ед. }\end{array}$ & $28-30$ & $32-35$ & $34-35$ \\
\hline $\begin{array}{c}\text { Общий показатель двигательный } \\
\text { памяти, (\%) }\end{array}$ & $20-22$ & $22-25$ & $22-25$ \\
\hline $\begin{array}{c}\text { Координация мышц сгибателей и } \\
\text { разгибателей, (\%) }\end{array}$ & $2,21-2,45$ & 10, оо-12,оо & 12, оо-14,0о \\
\hline
\end{tabular}

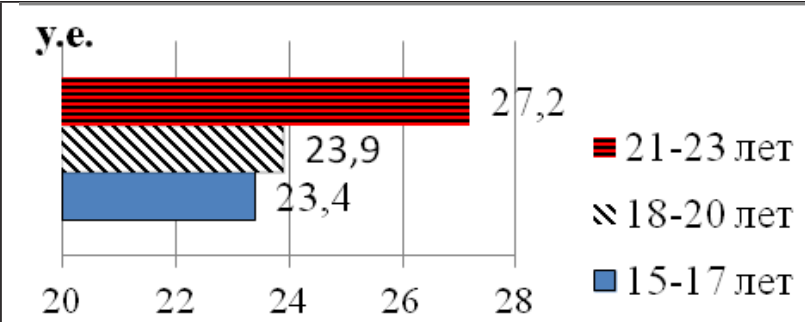

Рисунок 1 - Показатели точности реакции на движущийся объект у футболистов

На рисунке 1 представлена возрастная динамика показателей психоэмоционального состояния футболистов.

Точность реакции на движущийся объект у футболистов выделенных возрастных групп различаются в абсолютных средних значениях.

В группе 15-17 лет исходный показатель точности реакции на движущийся объект составил 23,4 \pm 2,02 ус.ед; в 18-19 лет - 23,9 \pm 1,54 ус.ед; в 20-21 лет он равнялся 27,2 \pm 2,04 ус.ед.

Точность реакции на движущийся объект у футболистов связана с

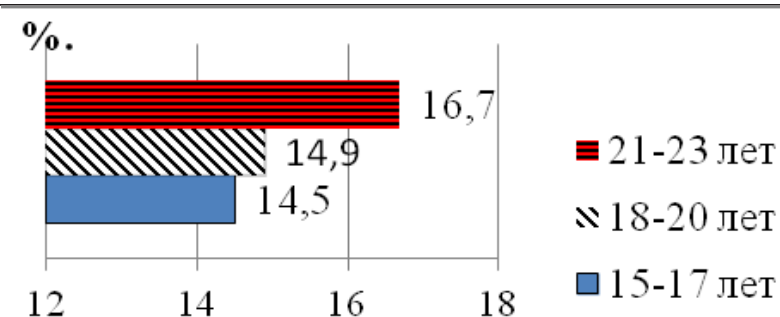

Рисунок 2 - Показатели коэффициента силы нервной системы футболистов

проявлением способности ориентироваться в пространстве и может выступать как оценка психоэмоционального состояния. У футболистов отмечается стабильный рост данного показателя как результат комплексного проявления физических способностей. Данный показатель имеет тенденцию к снижению при переутомлении и после ответственных стартов.

Показатели коэффициента силы и слабости нервной системы можно рассматривать как оценку доминанты торможения или возбуждения. У футболистов проявляются все виды силы и слабости нервной системы. У них 
наблюдается высокий уровень подвижности нервных процессов и легкость в возбуждении, что может привести к эмоциональным срывам.

Из рисунка 2 видно, что у футболистов отмечается изменение коэффициента силы и слабости нервной системы в процессе коррекции в сторону увеличения.

В группе 15-17 лет исходный показатель коэффициента силы и слабости нервной системы составил $14,8 \pm 1,31 \%$, а перед основной игрой он равнялся $14,5 \pm 1,45 \%$.

В группе футболистов 18-20 лет исходный показатель коэффициента силы и слабости нервной системы составил $14,5 \pm 1,31 \%$, а перед основной игрой он равнялся 14,9 \pm $1,57 \%$. Отмечаются возрастные различия, от чего может зависеть психоэмоциональное состояние футболистов. Так, как у футболистов 21-23 года наблюдается достоверно значимый результат по сравнению с таковым возрастных групп 15-17 и 18-20 лет.

Исходный показатель коэффициента силы и слабости нервной системы составил $15,56 \pm 1,61 \%$, а перед основным стартом, после предсоревновательной подготовки, он равнялся $16,7 \pm 2,01 \%$.

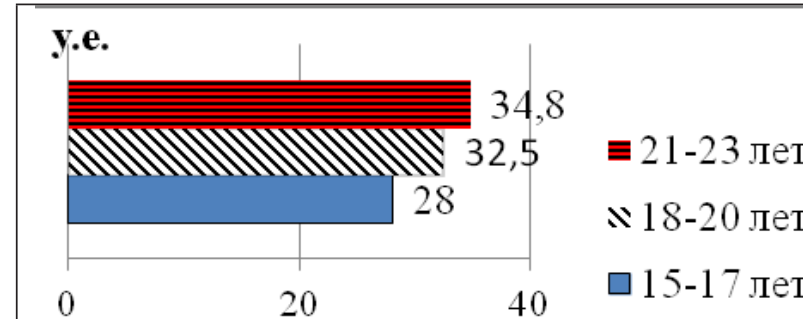

Рисунок 3 - Количество движений футболистов за 5 сек.

На рисунке 3 представлен показатель «Количество движений», выполняемых футболистами за 5 сек. Отмечено увеличение данного показателя у футболистов группы совершенствования спортивного мастерства. В нашем примере его использовали как одну из характеристик силы и слабости нервной системы футболистов. С повышением спортивного мастерства футболистов количество выполняемых действий увеличивается. Это связано прежде всего с тренировочными воздействиями скоростного характера. Футболисты больше тренируют скоростные и скоростно-силовые возможности и быстроту реакции на движущийся объект при продолжительном контроледействия соперника. При этом требуется постоянная коррекция психического состояния футболистов.

Общий показатель двигательной памяти характеризует объем, емкость и координацию двигательной памяти футболистов, которые можно использовать для оценки психоэмоционального состояния. Он изменяется

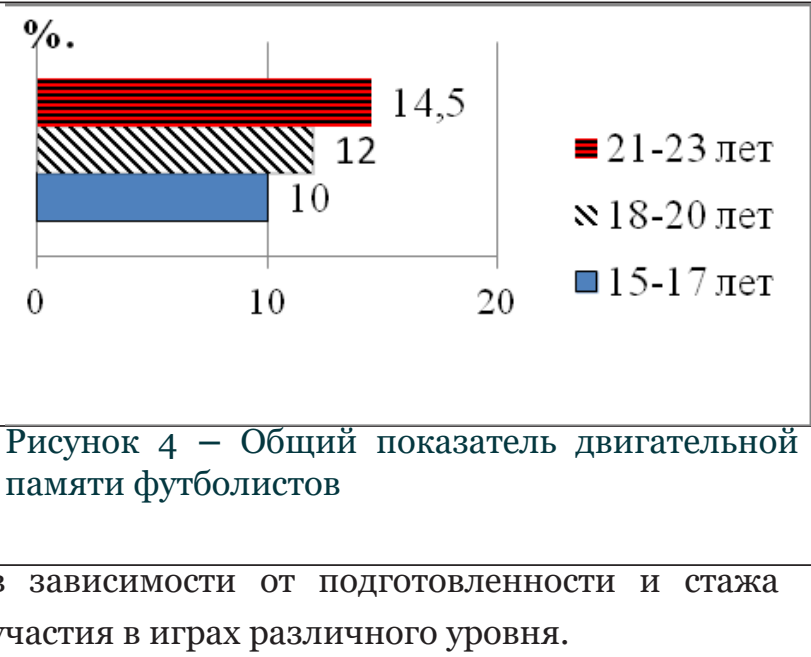

Из рисунка 4 видно, что возрастная динамика общего показателя двигательной памяти имеет тенденцию увеличения с возрастом.

В группе футболистов 15-17 лет общий показатель двигательной памяти составил 10,01 $\pm 1,21 \%$; в 18-20 лет он равнялся $12,0 \pm 1,11 \%$.

В 21-23 года общий показатель двигательной памяти составил $14,00 \pm 12,41$ ус.ед. В данном показателе также отмечается тенденция улучшения с возрастом, и это можно рассматривать как доказательную базу формирования устойчивого психоэмоционального состояния футболистов.

В диагностикепоказателя «Коэффициент координации мышц сгибателей и разгибателей» главным является необходимость выполнения движений на максимальной скорости, сохраняя при этом координацию движений и чувство темпа.

В группе футболистов 15-17 лет исходный 
показатель коэффициента координации мышц сгибателей и разгибателей составил 2,71 $\pm 2,01$ ус.ед.; в 18-20 лет - 3,67 \pm 2,01 ус.ед.; в 21-23 года $-4,77 \pm 2,21$ ус.ед.

Полученные

характеризующие

результаты, состояние футболистов, могут использоваться как для оценки психоэмоционального состояния, так и для модельной характеристики с учетом возраста футболистов. Представленные данные определены на основании многоразовых исследований каждой возрастной группы футболистов.

Учет диапазона колебаний изучаемых показателей психоэмоционального состояния футболистов, которые представлены в таблице 1, позволяет разработать комплекс саморегулирующих средств для формирования эффективного состояния психической готовности перед матчем.

C учетом представленного материала разработан профиль состояния психической готовности футболистов. В качестве основных компонентов профиля состояния психической готовности футболистов использованы следующие: мотивация достижения цели, избегания неудач и уверенность.
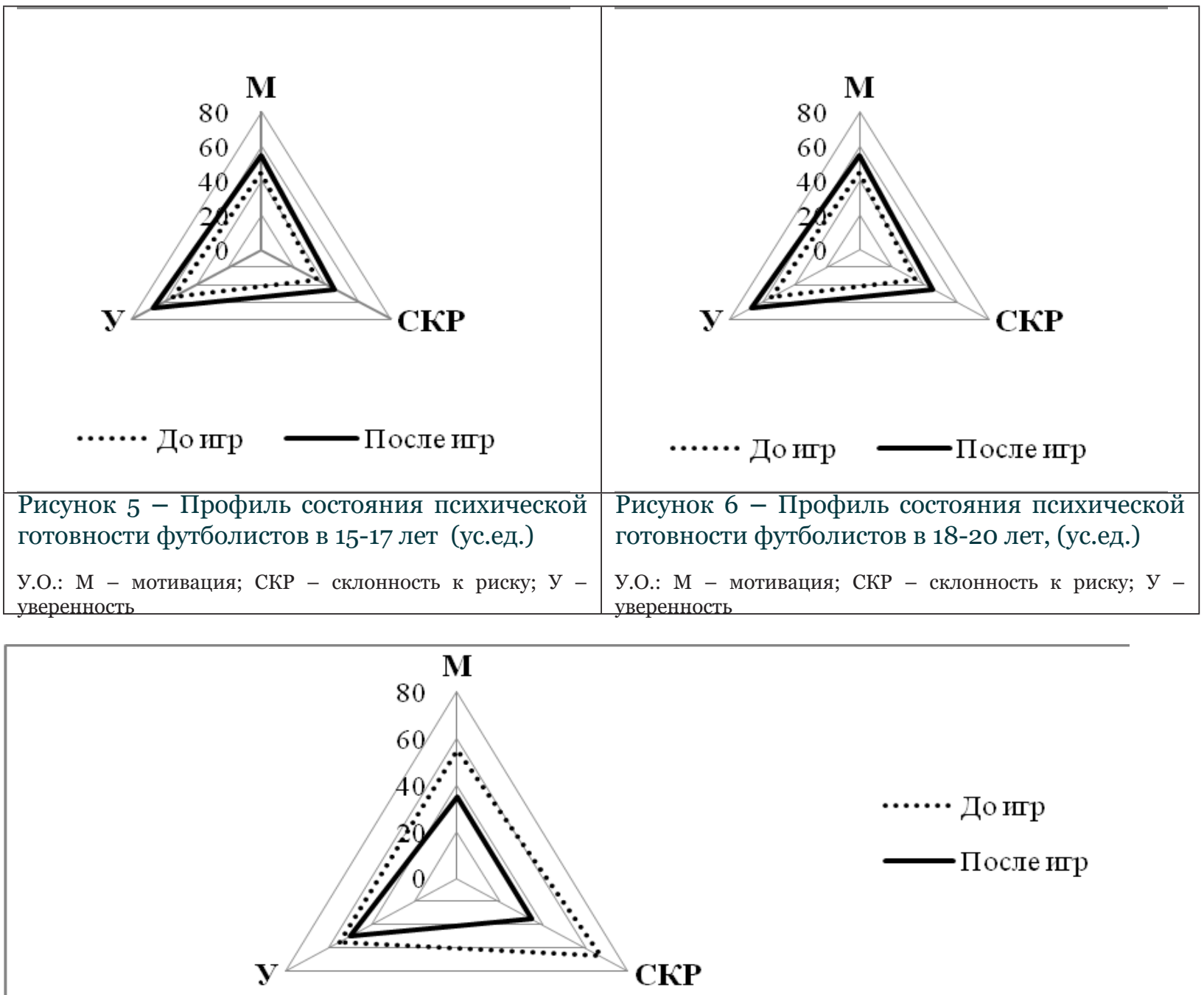

Рисунок 7 - Профиль состояния психической готовности футболистов в 21-23 года, (ус.ед). У.О. : М - мотивация; СКР - склонность к риску; У - уверенность 
Из рисунков 5,6,7 видно, что в возрастном аспекте проявления компонентов состояния психической готовности различаются. Особенно выражены компоненты в возрастной группе футболистов 21-23 лет. Следовательно, в зависимости от стажа и уровня подготовленности футболистов наблюдается высокий уровень состояния психической готовности к матчу, а после матча наблюдается снижение возбуждения, тогда как в возрастных группах 15-17 лет и 18-20 лет нервных возбуждений в состоянии психической готовности остается на определённое время, что требует снижения процесса эмоционального возбуждения за счет психорегулирующих средств.

\section{ЗАКЛЮЧЕНИЕ}

Таким образом, психоэмоциональное состояние футболистов зависит от возраста и этапов подготовки.

Учет модельного уровня и профиля психоэмоционального состояния и состояния психической готовности футболистов позволяет планировать подготовку с расширенным применением психорегулирующих средств подготовки.

\section{СПИСОК ЛИТЕРАТУРЫ}

1. Гордон С.М., Ильин А.Б. Оценка психологической готовности. Теория ипрактика физической культуры. 2004; 2: 45-49.

2. Кузнецов А.С. Психологическая подготовка в спортивной борьбе. Педагогикопсихологические и медико-биологические проблемы физической культуры и спорта. 2012; 7(2): 68-72.

3. Лабещенков О. В. Влияние психорегулирующий тренировки на функциональное состояние курсантов при занятиях воздушно-десантной подготовкой. Педагогико-психологические и медикобиологические проблемы физической культуры u cnopma. 2018; 13(4): 87-94. DOI: 10.14526/20704798-2018-13-4-87-94

4. Петухов А.В. Футбол. Формирование основ индивидуального технико-тактического мастерства юных футболистов. Проблемы и пути решения: Монография. Из-во «Советский спорта», г. Москва. 2006: 232.

5. Смоленцева В.Н. Психическая саморегуляция в процессе подготовки спортсменов. Омск: СибГУФК. 2003.

6. Смирнова В.В. Психологическое сопровождение подготовки борцов высокой квалификации. Теория u практика физ. культуры : Тренер: журнал в журнале. 2010; 6: 66-68.

7. Цагарелли Ю.А. Системная психологическая диагностика на приборе «Активациометр»: учебное пособие. Казань: ИУЭиП. 2004: 250.

8. Coetzee B., Grobbelaar H.W., Gird C.C. Sport psychological skills that distinguish successful from less successful soccer teams. Journal of Human Movement Studies. 2006; 51(6): 383-401.

9. MacNamara A., Button A., Collins D. The role of psychological characteristics in facilitating the pathway to elite performance: Part I: Identifying mental skills and behaviors. The Sport Psychologist. 2010; 24: 52-73.

10. Morris T. Psychological characteristics and talent identification in soccer. Journal of Sports Sciences. 2000; 18: 715-726. DOI: 10.1080/02640410050120096.

\section{Статья поступила в редакцию: 20.10.2020}

Козлов Алексей Анатольевич - тренер АО Футбольного клуба "Ростов», 344029, Россия, 2. Ростов-на-Дону, проспект Шолохова, дом 31E, e-mail: Stim.alexei@yandex.ru 